\title{
Whaling in Antarctic: apontamentos à decisão da Corte Internacional de Justiça
}

\author{
Lucas Carlos Lima*
}

\section{INTRODUÇÃO}

A sentença da Corte Internacional de Justiça (CIJ ou Corte) emitida em março de 2014 põe fim a um litígio iniciado em 2010 entre Austrália e Japão em relação às atividades de pesca à baleia realizadas pelo Segundo Programa Científico Baleeiro Japonês sob Permissão Especial (“JARPA II") no mar antártico. Através desta decisão, a Corte estabeleceu que as atividades baleeiras realizadas pelo programa japonês não constituíam uma exceção prevista no Artigo VIII da Convenção Internacional para a Regulamentação da Pesca da Baleia (CIRPB, Convenção ou Convenção Baleeira), sendo, portanto, contrárias às obrigações assumidas pelo Japão perante a Convenção. A Corte por fim decidiu que o Japão deveria revogar qualquer autorização emitida para pesca de baleias sob o programa JARPA II. ${ }^{1}$

O contexto em que o caso se insere não pode ser olvidado. O programa JARPA II iniciou suas atividades baleeiras em 2005 como sucessor do antigo programa JARPA, também alvo de criticismo. Em diversas ocasiões a Austrália contestou os programas japoneses. A alegação da Austrália seria de que o programa JARPA II teria apenas como escusa a finalidade científica, mas, em verdade, possuiria finalidades comerciais ${ }^{2}$, sobretudo porque a carne de baleia excedente dos programas científicos pode ser utilizada para consumo local. ${ }^{3}$

Tendo como fundamento das obrigações violadas a própria Convenção Baleeira, a base normativa da jurisdição da Corte no caso foi por sua vez a declaração facultativa de jurisdição obrigatória, prevista no artigo 36 do Estatuto da Corte. Parte dos dois mecanismos, a Nova Zelândia interveio no caso como terceiro interessado, nos termos do Artigo 63 do Estatuto da Corte 4 . Embora

\footnotetext{
Doutor em Direito Internacional pela Universidade de Macerata (Itália). Mestre em Direito
} Internacional pela Universidade Federal de Santa Catarina. 
algumas provocações processuais interessantes possam ser solevadas em relação a esta intervenção, a matéria não será discutida no presente ensaio.

Diversos são os aspectos do julgamento que merecem atenção e oferecerem elementos de reflexão, muito embora o enfoque do presente trabalho, seja a compreensão geral do caso e de alguns específicos elementos. A primeira parte do trabalho examinará a maneira como o mecanismo de jurisdição da CIJ foi acionado nesta controvérsia. A segunda parte focará na análise do background normativo da controvérsia, particularmente no sistema erigido pela CIRPB e os dispositivos desta que foram solevados no caso. A terceira parte enfocará na ratio decidendi da decisão, e em especial na questão da interpretação do termo "para fins de investigação científica” presente no Artigo VIII da CIRPB. Por fim, o caso oferece algumas reflexões sobre à relação entre Ciência, Direito e provas técnicas no âmbito do contencioso internacional que serão exploradas.

\section{A JURISDIÇÃO DA CORTE}

A primeira questão sobre a qual a Corte se debruçou foi, como de costume, verificar a existência ou não de sua jurisdição sob o caso em contenda, exercício oriundo do princípio Kompetenz-Kompetenz que rege as atividades de tribunais internacionais. ${ }^{5}$ Dentre os diversos métodos de atribuição de jurisdição previstos no artigo 36 do Estatuto ${ }^{6}$ da CIJ encontra-se a cláusula facultativa de jurisdição obrigatória (Art. 36.2 do Estatuto) ${ }^{7}$, através da qual os Estados podem voluntariamente submeter-se à jurisdição da Corte. Tanto Austrália quanto Japão realizaram referida declaração e, por consequência, estabeleceu-se a jurisdição da Corte.

Interessante notar que, apesar de ter realizado relativa declaração, o Japão contestou a jurisdição da Corte no presente caso com base na reserva à jurisdição estabelecida na declaração Australiana. Sendo as declarações realizadas sob o Artigo 36.2 regidas por um princípio de reciprocidade ${ }^{8}$, a Corte não poderia se pronunciar sobre matérias reservadas nas declarações de qualquer dos Estados em controvérsia. O Japão argumentou que as reclamações Australianas estariam, portanto, inclusas nas matérias que a Austrália elaborou reserva e, em especial:

any dispute concerning or relating to the delimitation of maritime zones, including the territorial sea, the exclusive economic zone and the continental shelf, or arising out of, concerning, or relating to the exploitation of any disputed area of or adjacent to any such maritime zone pending its delimitation. ${ }^{9}$

A interpretação esgrimada pelo Japão seria de que a questão das atividades baleeiras japonesas estariam incluídas no interior de referida zona marítima. A Corte afastou tal argumento com base em técnicas interpretativas 
elaboradas previamente em sua jurisprudência. Ela afirmou, por exemplo que a reserva deveria ser observada em sua unidade e que a real intenção da limitação Australiana se referia a questões meramente de delimitação e não propriamente atividades desenvolvidas numa determinada área. ${ }^{10}$ Portanto, não existiria um real motivo para que afastasse a jurisdição.

Particularmente interessante é o fato que o Japão concentrou sua argumentação na questão da reserva ao Artigo 36.2 e não em outros possíveis argumentos, como por exemplo, o interesse jurídico da Austrália em acionar o Japão em virtude da Convenção. Poder-se-ia questionar, por exemplo, que a Austrália não seria um Estado legitimado a acionar o Japão porque não teria sofrido um dano específico ou porque não teria um interesse específico na disputa. Contudo, o caso em comento parece tratar-se de um caso em que estão envolvidas obrigações erga omnes partes, ou seja, obrigações em que "cada Estado parte [do tratado] possui um interesse no cumprimento [das obrigações] em qualquer caso concreto" ${ }^{11}$. In concretu, existiria um específico interesse da Austrália, parte da CIRPB, em verificar o cumprimento por parte do Japão em relação às obrigações assumidas na Convenção. Vez que o Japão não levantou a objeção, a Corte não se pronunciou a respeito da questão. Contudo, aqui reside numa das "novas tendências" desenvolvidas na jurisprudência da Corte que é a resolução de conflitos oriundos de obrigações erga omnes e erga omnes partes. A estratégia judicial da Austrália de mesclar obrigações materiais existentes entre as partes com a jurisdição obrigatória do artigo 36.2 parece ser potencialmente importante em relação a questão de soluções de conflitos em matérias de direito internacional ambiental. ${ }^{12}$

\section{BACKGROUND NORMATIVO: A CONVENÇÃO PARA REGULAMENTAÇÃO DA PESCA DA BALEIA E SEU ARTIGO VIII}

A preocupação internacional em relação à regulamentação da atividade baleeira data dos anos 30, quando da expansão tecnológica que permitiu a intensificação desta atividade. Em brevíssimo resgate histórico, rememora-se que em 1931 foi firmada a Convenção para a Regulamentação da Pesca da Baleia. Referido tratado foi substituído em 1937 e, posteriormente, deu lugar à atual CIRPB $^{13}$, objeto do caso em litígio ${ }^{14}$. Firmada em 1946 e em vigor desde 1948, a CIRPB estabelece um regime para "apropriada conservação dos estoques de cetáceos e, portanto, tornar possível o desenvolvimento ordenado da indústria baleeira"15. Tanto Austrália quanto Japão fazem parte da Convenção Baleeira desde a década de 50.

O regime estabelecido pela Convenção ${ }^{16}$ possui alguns elementos normativos chave que foram objeto do litígio. Um destes elementos é a Agenda prevista no Artigo 1 da CIRPB, sujeita à frequente atualização pela Comissão Baleeira Internacional ${ }^{17}$ (CBI ou Comissão), organismo criado pela mesma 
Convenção. Este mecanismo permite que a CIRPB opere de maneira dinâmica, não exigindo que a Convenção seja emendada todas as vezes que atualizações se demonstrem necessárias, bastando emendas à Agenda realizadas Comissão. Nas palavras da própria Corte, "as funções conferidas à Comissão transformaram a Convenção num instrumento em evolução"18. Isto porque os dispositivos da Agenda são considerados parte integrante da Convenção e, consequentemente, suas violações são consideradas violações à própria Convenção.

Uma das funções atribuídas à Comissão é a definição das quantidades permitidas de pesca às baleias para finalidade comercial, bem como impor restrições à pesca da baleia tais como, por exemplo, a criação de zonas específicas de proteção, ou a proibição da utilização de certos métodos específicos de pesca. As discussões no seio da Comissão levaram a decretação em 1982, em vigor a partir de 1986, de uma proibição geral (moratória) a atividade comercial oriunda da pesca às baleias. Note-se, pois, que a Convenção não impunha uma proibição geral à atividade baleeira. Trata-se de um instrumento de cooperação que visava um controle harmônico deste recurso. As verdadeiras obrigações materiais de preservação e proibição originam-se na Agenda que adotou a moratória de $1986^{19}$. Este dado histórico reflete igualmente o desenvolvimento de instrumentos normativos internacionais relativos à proteção ambiental: é a sua evolução no decorrer do tempo (e sobretudo após a década de 70) que começa a permitir uma efetiva proteção de determinados setores do meio ambiente ${ }^{20}$.

Este é um dos essenciais pontos de divergência entre as partes no caso em comento. A Austrália defendeu uma interpretação evolutiva da Convenção arguindo que o instrumento se tornara essencialmente um instrumento para proteção e conservação de baleias. Por sua vez, o Japão utilizou de uma interpretação essencialmente restritiva do preâmbulo de que o objetivo principal da Convenção era o "ordenado desenvolvimento da indústria baleeira". A interpretação teleológica da Convenção parece ter sido um elemento chave nas discussões da Corte vez que objeto de diversas opiniões individuais dos juízes ${ }^{21}$.

Outras duas medidas importantes tomadas pela Comissão para a preservação de baleias, que se tornaram objetos de violação do caso em comento, foram a criação do Santuário do Atlântico Sul ${ }^{22}$ (Southern Ocean Sanctuary), região em que é totalmente proibida a pesca comercial de baleias, e a proibição do uso de factory ships ${ }^{23}$ para a pesca de baleias; seja para fins comerciais ou não comerciais $^{24}$.

O sistema de proteções erigidos pela CIRPB e atualizados pela sua Agenda, portanto, visam essencialmente a impossibilidade de execução de pesca à baleias com finalidade comercial a fim de garantir, também, a preservação dos cetáceos e, por consequência, o meio ambiente marinho. A única exceção permitida para a realização da pesca à baleia vem disciplinada pelo Artigo VIII da Convenção, que assim predispõe: 


\begin{abstract}
Não obstante o estabelecido nesta Convenção, qualquer dos Governos Contratantes poderá conceder a qualquer dos seus cidadãos uma licença especial autorizando esse cidadão a matar, capturar ou tratar baleias para fins de investigação científica, sujeita a restrições como a de número e a outras condições que o Governo Contratante considere apropriadas, e a morte, captura e tratamento de baleias de acordo com as condições deste artigo estarão isentas do estipulado nesta Convenção. Cada um dos Governos Contratantes comunicará de imediato à Comissão todas as licenças concedidas. Cada Governo Contratante poderá, em qualquer momento, revogar qualquer das licenças especiais concedidas. (grifo nosso)
\end{abstract}

Nota-se, portanto, que a execução de pesca à baleias com finalidade científica vem executada através de licenças emitidas pelos Estados membros da CIRPB. A questão central do caso Whaling in Antarctic refere-se às licenças emitidas pelo Japão para a execução do programa JARPA II e se tais licenças constituiriam "para fins de investigação científica" ("for purposes of scientific research"), o que foi arguido pelo Japão $0^{25}$.

Parte do debate residiu no grau de discricionariedade concedido pela Convenção aos Estados parte para a interpretação do termo e a concessão de licenças, o chamado debate sobre a margem de apreciação ${ }^{26}$. A argumentação japonesa neste ponto residia necessariamente na ideia que somente o Estado emissor da licença seria competente para avaliar se o programa consistiria ou não "para fins de investigação científica". A CIJ, todavia, entendeu que, por mais que o Artigo VIII da Convenção concedesse a um Estado parte a possibilidade de rejeitar uma licença ou especificar suas condições, a questão da definição do termo "para fins de investigação científica" não poderia consistir exclusivamente na "percepção do Estado"27. Assim sendo, coube à Corte a interpretação do termo "para fins de investigação científica”.

\title{
4. A DECISÃO: "PARA FINS DE INVESTIGAÇÃO CIENTÍFICA" E A QUESTÃO DA RELAÇÃO ENTRE CIÊNCIA E DIREITO
}

Como aludido, a questão fundamental do caso Whaling in Antarctic orbitava na interpretação a ser dada aos termos do Artigo VIII da CIRPB e no estabelecimento do programa japonês JARPA II como programa de finalidades científicas. Para resolver a questão, a Corte estabeleceu um standard of review (critério de revisão) específico que foi assim definido: 
Quando revisando a licença de uma permissão especial autorizando um cidadão a matar, capturar ou tratar baleias, a Corte irá avaliar, por primeiro, se o programa no qual estas atividades ocorrem envolvem investigação científica. Por segundo, a Corte irá considerar se a morte, captura ou tratamento de baleias é 'para fins de' investigação científica através examinando se, no uso de métodos letais, o design e a implementação do programa são razoáveis em relação à obtenção dos objetivos estabelecidos. Trata-se de um standard of review objetivo ${ }^{28}$.

Este foi o primeiro caso que a CIJ utilizou o conceito de standard of review em sua jurisprudência. Não é a primeira vez, contudo, que utiliza o princípio da razoabilidade ${ }^{29}$ para avaliar a conduta de um Estado no plano internacional, apesar do certo grau de discricionariedade que este exercício comporta. Contudo, parece ser positivo o fato da Corte estabelecer um objetivo critério para avaliação de termos específicos contidos em tratados internacionais; isto não significa afirmar, todavia, que este exercício não seja passível de críticas ou não apresente dificuldades em sua execução.

A primeira dificuldade enfrentada pela Corte para a solução da controvérsia reside no fato que a Convenção não especifica o termo "investigação científica" 30 . Contudo, no critério estabelecido pela Corte, não é o termo "investigação científica" que vem a ser enfrentado mas sim a determinação, através de uma interpretação razoável, do termo "para fins de investigação científica”. Nessa linha de pensar, a Corte esclareceu que a interpretação desta frase deveria ocorrer de forma cumulativa, de maneira que não bastaria a mera presença de um elemento de investigação/pesquisa científica para legitimar a exceção do Artigo VIII; em outras palavras, é necessário que a caça, a captura e o tratamento de baleias ocorram para as finalidades de investigação científica para que as atividades de um determinado programa configurem a exceção prevista no Artigo VIII da CIRPB ${ }^{31}$.

A definição dos termos "para fins de investigação científica" solevou a questão da relação entre Ciência e Direito no âmbito do direito internacional e qual é o papel de uma Corte no que se refere à definição da prova científica. As análises realizadas pela Corte e os argumentos estabelecidos pelas manifestaramse num arco de tecnicismos que, inter alia, variaram desde a necessidade de uso de métodos letais por parte do programa JARPA II até a análise da quantidade de baleias mortas para os propósitos científicos do programa. O uso de peritos (experts) apontados pelas partes, e sujeitos à cross-examination, neste caso foi, portanto, fundamental ${ }^{32}$ e de certa forma pareceram afastar o criticismo e as dúvidas solevadas no passado em relação à capacidade da Corte em lidar com evidências científicas complexas ${ }^{33}$. Apesar de não ter indicado seus próprios experts para a avaliação das provas apresentadas pelas partes, o ativo papel dos juízes na condução das audiências, questionando os experts, bem como seu uso ao longo da sentença, indicaram uma mais atenta abordagem da CIJ em relação a casos de complexa evidência. Nesse sentido pronunciou-se o Presidente da 
Corte, Peter Tomka, quando afirmou que "como o Julgamento [do caso Whaling in Antarctic] demonstra, este caso constitui prova incontroversa de que a Corte pode lidar com vastas quantidades de provas altamente técnicas e científicas de uma maneira cogente e metódica" ${ }^{34}$. O rigorismo da Corte em relação à prova técnica e científica parece ser uma clara e imediata resposta ao criticismo sofrido no caso Pulp Mills.

Contudo, a resposta da Corte parece ser significativa quanto à sua função no que se refere a questões científicas. É especialmente relevante, nesta linha argumentativa, a passagem em que a Corte nota a existência de um acordo entre os peritos das partes relativos ao uso de métodos letais, observando a existência de desacordo quanto às suas condições de uso. Por fim, a Corte aduz que "[a]s conclusões dos peritos enquanto cientistas, contudo, devem ser distinguidas da interpretação da Convenção, que é a tarefa desta Corte" ${ }^{35}$. Com esta frase, a Corte chama para si a última autoridade de manejar as provas técnicas e utilizá-las na compreensão do termo estabelecido pela Convenção e se as licenças outorgadas pelo Japão configuravam-se naquele termo.

No exercício de definir se estas licenças se configurariam ou não como de finalidade científica, a CIJ realizou interessantes constatações. Uma delas é relativo ao uso de métodos letais para realização de investigação científica, os quais não são inadmitidos, mas cuja quantidade pode ser significativa para considerar quão "para fins científicos" é um programa ${ }^{36}$. Contudo, o fato do Japão ter considerado pouco o uso de alternativas diversas de pesquisa que não o método letal parece ter enfraquecido a posição sustentada pelo Japão $0^{37}$. Outro exemplo interessante reside no fato de que a venda da carne de baleias e o uso dos rendimentos destas vendas seja utilizada para financiar pesquisas científicas não serem elementos suficientes, considerados isoladamente, para desconfigurar a finalidade científica no sentido do Artigo VIII, do programa ${ }^{38}$. Com efeito, a CIJ enfocou em outros critérios para estabelecer uma decisão, como a escala do uso de amostragem letal, que "pode sugerir que a pesca à baleia è para razões outras que investigação científica"39. Utilizando o critério de razoabilidade, a Corte esclareceu que um de seus objetivos era avaliar se a evidência apresentada suportava a conclusão que as amostras coletadas pelo programa JARPA II eram razoáveis em relação à obtenção dos objetivos estatuídos pelo programa ${ }^{40}$. Um terceiro elemento que contribuiu para formar a convicção da Corte em relação à não-configuração do programa JARPA II como de finalidade científica foi a circunstância do Japão não ter jamais modificado os objetivos do programa JARPA nem a quantidade de amostras coletadas ${ }^{41}$. Ademais, o fato dos peritos terem concordado (incluindo aqui o perito apontado pelo Japão) com a falta de transparência do programa em relação a definição de determinados critérios para caça de baleias minke parece também ter sido em levado em consideração pela Corte ${ }^{42}$.

Ao analisar toda a massa de evidências e as eventuais inconsistências do programa JARPA II, a Corte por fim concluiu que: 
No seu complexo, a Corte considera que o JARPA II envolve atividades que podem ser largamente caracterizados como investigação científica, mas as evidências não estabelecem que seu design e a implementação são razoáveis na conquista dos seus declarados objetivos. A Corte concluiu que as licenças especiais garantidas ao Japão para matar, capturar e tratar baleias em conexão com o programa JARPA II não são 'para fins de investigação científica' de acordo com o Artigo VIII, parágrafo 1, da Convenção ${ }^{43}$.

Uma vez verificado que o programa JARPA II não se configurava como um programa "para fins de investigação científica", a Corte debruçou-se aos três dispositivos da Agenda Baleeira supra mencionados: a) a violação à moratória à pesca comercial de baleias; b) a violação à pesca de baleias no Santuário do Atlântico e; c) a violação da moratória do uso de factory ships para a pesca comercial de baleias. A Corte considerou, portanto, que em não recaindo na exceção do Artigo VIII, estes três dispositivos estavam sendo violados pelo Japão.

Por fim, último interessante ponto foi em relação às medidas de implementação (remedies) tomadas pela Corte. Ao considerar que o programa JARPA II era ainda ativo e em funcionamento, a Corte aduziu que eram necessárias medidas que fossem além de natureza declaratória. Deste modo, a Corte ordenou ao Japão a revogação de qualquer licença para matar, capturar ou tratar baleias e evitar a emissão de qualquer outra licença relativa ao programa ${ }^{44}$. A decisão foi imediatamente acolhida pelo Japão, que suspendeu as atividades do programa JARPA II.

\section{APONTAMENTOS CONCLUSIVOS}

Um dos mais complexos e técnicos casos perante a Corte Internacional de Justiça em tempos recentes, o caso Whaling in Antarctic oferece interessantes elementos para reflexão, alguns dos quais já evidenciados nas argumentações supra esgrimadas. Mais do que conclusões definitivas, o caso parece soerguer problemas que será a própria Corte a responder no futuro (talvez recente). Por diversas razões, este caso parece refletir uma série de novas tendências existentes no contencioso internacional e, em particular, descortinar uma Corte Internacional de Justiça que se demonstra atenta a estas novas tendências, preservando o equilíbrio entre as partes ${ }^{45}$.

Uma das possíveis lentes de observação a serem empregadas para a análise do caso é a do direito internacional ambiental e de sua inserção nos sempre constantes debates acerca da questão ambiental que conquista espaço no contencioso internacional. Embora ativistas pudessem esperar um papel mais enérgico da Corte em relação aos eventuais danos ao meio ambiente marinho e 
aos objetivos primordiais da CIRPB, a linha de raciocínio jurídico adotada pela Corte pareceu conduzir a uma efetiva decisão que tocou importantes argumentos do direito ambiental internacional. Como relembra Rosalyn Higgins, o direito ambiental não é realmente um "self contained topic"46 e esta decisão da Corte reforça esta ideia quando remaneja à discussão para a interpretação dos termos relativos à "finalidade científica" no sentido do Artigo VIII da CIRPB.

Nessa linha de pensar, no que se refere à jurisdição da Corte, pode-se esperar no futuro novas ocasiões da Corte enfrentando questões concernentes a obrigações erga omnes partes nos mesmos moldes do caso Whaling; sobretudo de natureza ambiental. $\mathrm{O}$ atual caso em discussão perante a corte entre Ilhas Marshall e Reino Unido relativo às obrigações do Tratado de Não Proliferação de Armas Nucleares parece confirmar este $\mathrm{uso}^{47}$.

O segundo elemento importante que emerge do caso, como evidenciado, é o crescimento de questões de alta complexidade técnica sendo objetos de litígios internacionais e a resposta dos tribunais em lidar com estas evidências. A leitura do julgamento demonstra a tecnicidade das questões solevadas, bem como a importância das provas apresentadas pelas partes para a decisão da questão. Este crescimento coloca juízes - profissionais essencialmente treinados em técnicas jurídicas - na difícil posição de avaliar a evidência apresentada através dos instrumentos à disposição de uma determinada corte ou tribunal. Nota-se que o papel dos experts é e foi decisivo para a condução do procedimento. $\mathrm{O}$ desempenho da Corte ao lidar com este material probatório complexo parece não demonstrar somente que pode resolver casos desta natureza, como afirmou o Presidente Tomka, mas que responde às críticas que lhe foram endereçadas no passado. Esse constante aprimoramento do procedimento baseado numa dialética entre criticismo-resposta da Corte é primordial para um órgão de solução de controvérsias entre Estados como é a Corte, que direta ou indiretamente depende da "confiança" dos Estados para a submissão de controvérsias à sua jurisdição. Em último grau, o aprimoramento da Corte é o adimplemento de sua função essencial no interior do sistema das Nações Unidas de resolver controvérsias pacificamente.

Pode-se igualmente concentrar nos efeitos práticos da decisão. Por mais que possa existir alguma expectativa de que o julgamento significasse o fim das atividades baleeiras do Japão, esta não parece, todavia, ser uma realidade. O Japão parece inclinado a adimplir a decisão que, como evidenciado, restringe-se ao programa JARPA II; o que não o impedirá de buscar novas licenças e desenvolver novos programas científicos - esta é uma faculdade da própria CIRPB e sua Agenda. Contudo, a existência da decisão será fundamental para o aprimoramento de novos programas "para fins de investigação científica”. A própria Corte parece estar consciente desta questão quando, na parte do julgamento em que enfrenta as medidas de implementação, ela aduz que "é esperado que o Japão leve em consideração o raciocínio e as conclusões contidas no Julgamento quando ele considerar a possibilidade de emitir quaisquer futuras licenças sob o Artigo VIII, parágrafo 1, da Convenção" ${ }^{48}$. Autores suportam a ideia de que Japão levará em 
conta o criticismo da Corte e tentará adotar um novo programa científico para continuar a desenvolver suas atividades comerciais ${ }^{49}$.

A observação do cumprimento e dos efeitos da sentença no caso Whaling in Antarctic é particularmente interessante, seja porque oferece elementos de reflexão ao cumprimento das sentenças internacionais por parte dos Estados, seja porque concretamente o Japão pode se ver envolvido em litígios internacionais futuros devido às tensões jurídicas na região asiática. $\mathrm{O}$ cumprimento com a decisão da Corte e os critérios por ela adotados na avaliação do programa científico JARPA II emergem, consequentemente, como fundamentais.

\section{NOTAS}

1 Whaling in the Antarctic (Australia v. Japan: New Zealand intervening), Judgment, I.C.J. Reports 2015, parte dispositiva número 7 .

2 Whaling in the Antarctic (Australia v. Japan: New Zealand intervening), Memorial of Australia, pp.261 ss.

3 Cfr. Artigo 13, (b), da Agenda da Convenção Internacional para a Regulamentação da Pesca à Baleia.

4 Whaling in the Antarctic (Australia v. Japan: New Zealand intervening), Declaration of Intervention of New Zealand, Order of 6 February 2013, I.C.J. Reports 2013, p. 3 ss. Quanto a questão te intervenção no procedimento da Corte, ver: BONAFE, B., La protezione degli interessi di Stati terzi davanti alla Corte Internazionale di Giustizia. Napoli: Editoriale Scientifica, 2014; PALCHETTI P., La protection des intérêts d'Etats tiers par la Cour internationale de Justice: l'affaire de la Frontière terrestre et maritime entre le Caméroun et le Nigéria, in Revue Général de Droit International Public, 2003, p. 865-883; PAULUS A., Article 66, in ZIMMERMANN, A.; TOMUSCHAT, C.; OELLERS-FRAHM (Orgs.), The Statute of the International Court of Justice: a Commentary. Oxford: OUP, 2012, p. 1427-1443.

5 Sobre o princípio, Tomuschat escreveu que "It is a rule generally encountered in the status of international courts and tribunals that the judicial body concerned decides on its jurisdiction should any doubt arise. It enjoys Kompetenz-Kompetenz. Were it otherwise, the authority of the eventual judicial findings would be gravely compromised. Only if a judicial body is empowered to make binding determinations on all the issues which arise during a proceeding brought before it, is it able to issue an unchallengeable judicial determination" em TOMUSCHAT, Article 36, In ZIMMERMANN, A.; TOMUSCHAT, C.; OELLERS-FRAHM (Orgs.), The Statute of the International Court of Justice: a Commentary. Oxford: OUP, 2012, p. 694.

6 Artigo 36. 1. A competência da Côrte abrange tôdas as questões que as partes lhe submetam, bem como todos os assuntos especialmente previstos na Carta das Nações Unidas ou em tratados e convenções em vigor. 2. Os Estados partes no presente Estatuto poderão, em qualquer momento, declarar que reconhecem como obrigatória, ipso facto e sem acôrdo especial, em relação a qualquer outro Estado que aceite a mesma obrigação, a jurisdição da Côrte em todas as controvérsias de ordem jurídica que tenham por objeto: a) a interpretação de um tratado; b) qualquer ponto de direito internacional; c) a existência de qualquer fato que, se verificado, constituiria a violação de um compromisso internacional; d) a natureza ou a extensão da reparação devida pela rutura de um compromisso internacional. 3. As declarações acima mencionadas poderão ser feitas pura e simplesmente ou sob condição de reciprocidade da parte de vários ou de certos Estados, ou por -prazo determinado. 4. Tais declarações serão depositadas junto ao Secretário Geral das Nações Unidas, que as transmitirá, por cópia, às partes contratantes do presente Estatuto e ao Escrivão 
da Côrte. 5. Nas relações entre as partes contratantes do presente Estatuto, as declarações feitas de acôrdo com o artigo 36 do Estatuto da Côrte Permanente de Justiça Internacional e que ainda estejam em vigor serão consideradas como importando na aceitação da jurisdição obrigatória da Côrte Internacional de Justiça pelo período em que ainda devem vigorar e de conformidade com os seus têrmos. 6. Qualquer controvérsia sôbre a jurisdição da Côrte será resolvida por decisão da própria Côrte.

7 Sobre a questão ver TOMUSCHAT, cit. e ROSENNE, S., The Law and the Practice of International Court of Justice, 1920-2005. Leiden: Martinus Nijhoff, 2006, pp. 701-797. Rosenne assim a define: "The Court explained that when a State deposits a declaration with the Secretary-General of the United Nations in accordance with Article 36, paragraph 4, of the Statute, that State becomes a party to the 'system of the Optional Clause' in relation to the other States making declarations, with all the rights and obligations deriving from Article 36. This includes the right to institute proceedings unilaterally against another State which is a party to the system of the optional clause, and the obligation to accept jurisdiction invoked against it by such other State. This refers both to the States which are parties to the system at the time of the declaration, and to those which may become party to it at some future date".

8 Como previsto no Artigo 36.3 do Estatuto da CIJ. Sobre a questão, ver TOMUSCHAT, cit., e igualmente ALEXANDROV, S.A., Accepting the Compulsory Jurisdiction of the International Court of Justice with Reservations: An Overview of Practice with a Focus on Recent Trends and Cases, in: Leiden Journal of International Law n. 14, 2001, pp.89-124.

9 Whaling in Antarctic, Judgment, para. 31, p. 19, referindo-se à alínea (b) da declaração Australiana de 22 de Março de 2002.

10 Whaling in Antarctic, Judgment, p. 21, para. 37-39.

11 Questions relating to the Obligation to Prosecute or Extradite (Belgium v. Senegal), Judgment, I.C.J. Reports 2012, p. 449, para. 68. Neste sentido, a Corte assim pronunciou-se "That common interest implies that the obligations in question are owed by any State party to all the other States parties to the Convention. All the States parties "have a legal interest" in the protection of the rights involved (Barcelona Traction, Light and Power Company, Limited (Belgium v. Spain), Second Phase, Judgment, I.C.J. Reports 1970, p. 32, para. 33). These obligations may be defined as 'obligations erga omnes partes' in the sense that each State party has an interest in compliance with them in any given case"

12 Sobre o litígio de questões ambientais no contencioso internacional e seus desafios, ver BOYLE, A., HARRISON, J., Judicial Settlement of International Environmental Disputes: Current Problems, in Journal of International Dispute Settlement, Vol. 4, No. 2, pp.245-276, 2013.

13 HALVORSSEN, A.M. The origin and development of international environmental law. in ALAM et. al (Orgs) Routledge Handbook of International Environmental Law. New York: Routledge 2013, p. 78

14 Sobre a Convenção Baleeira, ver, FITZMAURICE, M. The International Convention for the Regulation of Whaling and International Whaling Commission : Conservation or Preservation : can the Gordian Knot be cut (or untangled)?, In: The Yearbook of Polar Law, vol. 5, 2013, pp. 451-490.

15 CIRPB, Preâmbulo.

16 A teoria dos regimes pode ser aplicada à CIRPB, como argumentam propriamente Birnie, Boyle e Redgwell: "Often referred to as 'international regimes', multilateral environmental agreements (MEAs) with their related protocols and soft law have been employed by states and international institutions to provide a regulatory system capable of dynamic evolution. The strength of the regime model of governance is the opportunity it off ers for multilateral solutions to environmental problems and the negotiated application and development of international legal standards. It enables states to exercise a fiduciary or trusteeship role in the protection of the environment, other species, and future generations". Sobre a questão ver, BIRNIE, P.; BOYLE, A.; REDGWELL, C. International Law \& The Environment. 3a Edicao. Oxford: OUP, 2009. pp.84-86. 
17 Trata-se de órgão central da CIRPB composto por um membro de cada Estado parte da Convenção. Sobre a Comissão, ver o Artigo 3 da CIRPB.

18 Whaling in Antarctic, Judgment, para. 45, p. 23.

19 A moratória vem expressa no Artigo 10, (e), da Agenda da CIRPB, que assim dispõe: "Notwithstanding the other provisions of paragraph 10, catch limits for the killing for commercial purposes of whales from all stocks for the 1986 coastal and the 1985/86 pelagic seasons and thereafter shall be zero. This provision will be kept under review, based upon the best scientific advice, and by 1990 at the latest the Commission will undertake a comprehensive assessment of the effects of this decision on whale stocks and consider modification of this provision and the establishment of other catch limits".

20 Cfr. BOISSON DE CHAZOURNES, Laurence. Features and trends in international environmental law. In: Kerbrat, Yvan and Maljean-Dubois, Sandrine (Ed.). The transformation of international environmental law. Oxford: Pedone, 2011. p. 9 - 20.

21 Nesse sentido ver, especialmente, as opiniões dissidentes dos juízes Owada, Abraham e Yusuf. Por outro viés, ver as opiniões dos juízes Cançado Trindade e da juíza ad hoc Charlesworth. Interessante visão de equilíbrio, que parece ter sido a visão adotada pela Corte é do juíz Greenwood que afirmou "I do not find either of these approaches wholly persuasive. Australia's approach is difficult to reconcile with the language of the Preamble and, in particular, the passage quoted in the preceding paragraph. The language of the Convention and its travaux préparatoires make clear that an important objective of the Convention was to ensure a future for the whaling industry by making sustainable whaling possible. On the other hand, Japan's argument that the Convention treats conservation as wholly subordinate to the development of whaling is also untenable. The Preamble shows that both conservation and ensuring a future for sustainable whaling were considered to be purposes of the Convention". In Whaling in Antarctic, Separate Opinion of Judge Greenwood, para. 4, p.2.

22 Artigo 7, (b) da Agenda da Convenção Baleeira, que assim dispõe: "In accordance with Article $V(1)(c)$ of the Convention, commercial whaling, whether by pelagic operations or from land stations, is prohibited in a region designated as the Southern Ocean Sanctuary. This Sanctuary comprises the waters of the Southern Hemisphere southwards of the following line: starting from 40 degrees $S, 50$ degrees $W$; thence due east to 20 degrees $E$; thence due south to 55 degrees $S$; thence due east to 130 degrees $E$; thence due north to 40 degrees $S$; thence due east to 130 degrees $W$; thence due south to 60 degrees $S$; thence due east to 50 degrees $W$; thence due north to the point of beginning. This prohibition applies irrespective of the conservation status of baleen and toothed whale stocks in this Sanctuary, as may from time to time be determined by the Commission".

23 O Artigo II, para. 1, da Convenção define "Factory ship" como "a ship in which or on which whales are treated either wholly or in part". O uso de factory ships aumentou drasticamente a caça às baleias no passado, motivo pelo qual seu uso foi adotado pela Agenda como proibido.

24 Artigo 10, (d) da Agenda da Convenção Baleeira, que assim dispõe: "Notwithstanding the other provisions of paragraph 10 there shall be a moratorium on the taking, killing or treating of whales, except minke whales, by factory ships or whale catchers attached to factory ships. This moratorium applies to sperm whales, killer whales and baleen whales, except minke whales".

25 Whaling in Antarctic, Judgment, para. 49, p.25.

26 Sobre a questão, ver GRUSZCZYNSKI, L., WERNER, W. Deference in International Courts and Tribunals: Standard of Review and Margin of Appreciation, Oxford: OUP, 2014; LETSAS, G., Two Concepts of the Margin of Appreciation, in Oxford Journal of Legal Studies, pp.705 ss, 2006. em especial; RAGNI, C. Interpretazione dei Trattati e Standard of Review nella Giurisprudenza della Corte Internazionale di Giustizia: Riflessioni Sull'Affare della Caccia alla Balena nell'Antartico, in Rivista di Diritto Internazionale, Vol. 3, 2014, pp.725-760.

27 Whaling in Antarctic, Judgment, para. 61, p.28. 
28 Whaling in Antarctic, Judgment, para. 67, p.29. Do original: “When reviewing the grant of a special permit authorizing the killing, taking and treating of whales, the Court will assess, first, whether the programme under which these activities occur involves scientific research. Secondly, the Court will consider if the killing, taking and treating of whales is "for purposes of" scientific research by examining whether, in the use of lethal methods, the programme's design and implementation are reasonable in relation to achieving its stated objectives. This standard of review is an objective one. Relevant elements of a programme's design and implementation are set forth below (see paragraph 88)".

29 Neste sentido ver, RAGNI, cit., pp.749 ss.

30 Whaling in Antarctic, Judgment, para. 73, p.30.

31 Ibidem., para. 71., p.30.

32 Sobre a questão da relação entre Ciência e Direito no caso Whaling in Antarctic, ver MBENGUE, M., Between law and science: A commentary on the Whaling in the Antarctic case, in Questions of International Law, Napoli: Editoriale Scientifica, 2015, pp.3-12; SCOVAZZI, T.Between law and science: Some considerations inspired by the Whaling in the Antarctic judgment, in Questions of International Law, Napoli: Editoriale Scientifica, 2015, pp.13-30; LIMA, L., Weighing the evidential value of expert opinion: The Whaling Case, in Questions of International Law, Napoli: Editoriale Scientifica, 2015, pp.31-38; FOSTER, C.E., New Clothes for the Emperor? Consultation of Experts by the International Court of Justice, in Journal of International Dispute Settlement, 2013, pp.1-34. E de maneira geral: FOSTER, C.E., Science and Precautionary Principle in International Courts and Tribunals. Cambridge: CUP, 2011; ALVAREZ, J.E., Are International Judges Afraid of Science? A Comment on Mbengue, in 34 Loyola L.A. International and Comparative Law Review, 2011, pp. 81-98.

33 A questão foi especialmente levantada no caso PulpMills (Argentina v. Uruguai), que acendeu a discussão acerca do papel que os peritos possuem no contexto probatório da Corte. A questão ganha notável relevo quando, em sua opinião dissidente conjunta neste caso, os juízes Simma e Al-Khazawneh criticam severamente o posicionamento da Corte quanto a esta temática, o que vem seguido na doutrina. Para mais sobre a questão, ver FOSTER, C.E. New Clothes, cit.

34 TOMKA, P. Speech to the sixth committee of the General Assembly of the United Nations, delivered in 31 October 2014, p. 2.

35 Whaling in Antarctic, Judgment, para.82, p.31. Do original: "The Court observes that, as a matter of scientific opinion, the experts called by the Parties agreed that lethal methods can have a place in scientific research, while not necessarily agreeing on the conditions for their use. Their conclusions as scientists, however, must be distinguished from the interpretation of the Convention, which is the task of this Court".

36 Whaling in Antarctic, Judgment, paras. 128-132, p. 42.

37 Ibidem, para. 144, p. 45.

38 Ibidem, para. .94 , p. 34.

39 Idem.

40 Ibidem, para. 172, pp.51-52.

41 Ibidem, para. 209, p. 61.

42 Ibidem, para. 225, p. 65.

43 Ibidem, para.227, p. 65. No original: "Taken as a whole, the Court considers that JARPA II involves activities that can broadly be characterized as scientific research (see paragraph 127 above), but that the evidence does not establish that the programme's design and implementation are reasonable in relation to achieving its stated objectives. The Court concludes that the special permits granted by Japan for the killing, taking and treating of whales in connection with JARPA II are not "for purposes of scientific research" pursuant to Article VIII, paragraph 1, of the Convention". 
44 Ibidem, para. 245, p. 70.

45 Neste sentido são particularmente as reflexões de ABI-SAAB, G. The International Court as a world court. In LOWE, V.; FITZMAURICE, M. (Org.). Fifty Years of the International Court of Justice. Cambridge: CUP, 1996, p. 14.

46 HIGGINS, R. Respecting Sovereign States and Running a Tight Courtroom, in The international and comparative law quarterly, Vol. 50, Issue 1, pp.121-132.

47 Obligations concerning Negotiations relating to Cessation of the Nuclear Arms Race and to Nuclear Disarmament (Marshall Islands v. United Kingdom), Application instituting proceedings against the United Kingdom of Great Britain and Northern Ireland, 24 April 2014.

48 Ibidem, para. 246, p.70.

49 CLAPHAM, P.J. Japan's whaling following the International Court of Justice ruling: Brave New World - Or business as usual? In Marine Policy, Volume 51, Janeiro, 2015, p.240.

\section{Referencias Bibliográficas}

ABI-SAAB, G. The International Court as a world court. In LOWE, V.; FITZMAURICE, M. (Org.). Fifty Years of the International Court of Justice. Cambridge: CUP, 1996, p. 14.

ALEXANDROV, S.A., Accepting the Compulsory Jurisdiction of the International Court of Justice with Reservations: An Overview of Practice with a Focus on Recent Trends and Cases, in: Leiden Journal of International Law n. 14, 2001, pp.89-124.

ALVAREZ, J.E., Are International Judges Afraid of Science? A Comment on Mbengue, in 34 Loyola L.A. International and Comparative Law Review, 2011, pp.81-98.

BIRNIE, P.; BOYLE, A.; REDGWELL, C. International Law \& The Environment. 3a Edicao. Oxford: OUP, 2009.

BOISSON DE CHAZOURNES, Laurence. Features and trends in international environmental law. In: Kerbrat, Yvan and Maljean-Dubois, Sandrine (Ed.). The transformation of international environmental law. Oxford: Pedone, 2011. p. 9 - 20.

BONAFÈ, B., La protezione degli interessi di Stati terzi davanti alla Corte Internazionale di Giustizia. Napoli: Editoriale Scientifica, 2014.

BOYLE, A., HARRISON, J., Judicial Settlement of International Environmental Disputes: Current Problems, in Journal of International Dispute Settlement, Vol. 4, No. 2, pp. 245 276, 2013.

CLAPHAM, P.J. Japan's whaling following the International Court of Justice ruling: Brave New World - Or business as usual? In Marine Policy, Volume 51, Janeiro, 2015. pp.238-242

FITZMAURICE, M. The International Convention for the Regulation of Whaling and International Whaling Commission : Conservation or Preservation: can the Gordian Knot be cut (or untangled)?, In: The Yearbook of Polar Law, vol. 5, 2013, pag. 451-490. 
FOSTER, C.E., New Clothes for the Emperor? Consultation of Experts by the International Court of Justice, in Journal of International Dispute Settlement, 2013, pp.1-34.

FOSTER, C.E., Science and Precautionary Principle in International Courts and Tribunals. Cambridge: CUP, 2011.

GEDDIS, E., RIDINGS, P. Whaling in the Antarctic: Some Reflections by Counsel. In: New Zealand Yearbook of International Law, Volume 11, 2013.

HALVORSSEN, A.M. The origin and development of international environmental law. in ALAM et. al (Orgs) Routledge Handbook of International Environmental Law. New York: Routledge 2013, p.78

HARIMOTO, Y. The ICJ Judgment on the Whaling Case: Some Reflections. In AALCO Journal of International Law. Vol. 3. Issue 1. 2014. pp.31-44.

LIMA, L., Weighing the evidential value of expert opinion: The Whaling Case, in Questions of International Law, Napoli: Editoriale Scientifica, 2015, pp.31-38.

MBENGUE, M., Between law and science: A commentary on the Whaling in the Antarctic case, in Questions of International Law, Napoli: Editoriale Scientifica, 2015, pp.3-12;

PALCHETTI P., La protection des intérêts d'Etats tiers par la Cour internationale de Justice: l'affaire de la Frontière terrestre et maritime entre le Caméroun et le Nigéria, in Revue Général de Droit International Public, 2003, p. 865-883.

PAULUS A., Article 66, in ZIMMERMANN, A.; TOMUSCHAT, C.; OELLERS-FRAHM (Orgs.), The Statute of the International Court of Justice: a Commentary. Oxford: OUP, 2012, p. 1427-1443.

PAYNE, C.R. Australia v. Japan: ICJ Halts Antarctic Whaling. In: ASIL Insights, Vol. 18, Issue 9, 2014. Disponivel em: http://www.asil.org/insights/volume/18/issue/9/australiav-japan-icj-halts-antarctic-whaling\#_edn4

RAGNI, C. Interpretazione dei Trattati e Standard of Review nella Giurisprudenza della Corte Internazionale di Giustizia: Riflessioni Sull'Affare della Caccia alla Balena nell'Antartico, in Rivista di Diritto Internazionale, Vol. 3, 2014, pp.725-760.

RAGNI, C. Standard of Review and Margin of Appreciation before the International Court of Justice. In GRUSZCZYNSKI, L., WERNER, W. Deference in International Courts and Tribunals: Standard of Review and Margin of Appreciation, Oxford: OUP, 2014.

ROSENNE, S., The Law and the Practice of International Court of Justice, 1920-2005. Leiden: Martinus Nijhoff, 2006.

SCOVAZZI, T. Between law and science: Some considerations inspired by the Whaling in the Antarctic judgment, in Questions of International Law, Napoli: Editoriale Scientifica, 2015, pp.13-30; 
SMITH, J.J.P. A Double-Edged Harpoon: The Trial of Science in the Antarctic Whaling Case before the International Court of Justice, in: 28 Ocean Yearbook, 2014. pp.445-495.

TOMUSCHAT, Article 36, In ZIMMERMANN, A.; TOMUSCHAT, C.; OELLERSFRAHM (Orgs.), The Statute of the International Court of Justice: a Commentary. Oxford: OUP, 2012. 


\section{Resumo}

A decisão da Corte Internacional de Justiça no caso Whaling in Antarctic (Australia v. Japão, Nova Zelândia interveniente) é um dos casos mais técnicos e complexos de sua jurisprudência recente. O presente trabalho analisa e discute este julgamento enfocando nos principais argumentos utilizados pela Corte, particularmente enfrentando as questões de standard of review e a interpretação do termo "para fins de investigação científica" presente no Artigo VIII da Convenção Internacional para Regulamentação da Pesca à Baleia. Ademais, este trabalho também examina os elementos oferecidos pela decisão quanto a relação entre Ciência e Direito.

Palavras-chave: Corte Internacional de Justiça. Direito Ambiental Internacional. Caso Whaling in Antarctic. 


\title{
WHALING IN ANTARTIC: NOTES TO THE DECISION OF THE INTERNATIONAL COURT OF JUSTICE
}

\begin{abstract}
The judgment rendered by the International Court of Justice concerning the case Whaling in Antarctic (Australia v. Japan, New Zealand intervening) is one of the most technical and complex cases which the Court has faced in its recent case law. The present paper analyses and discusses the mentioned judgment focusing on the main arguments laid out by the Court, particularly the issues of "standard of review" and the interpretation of the term "for purposes of scientific research" present in Article VIII of the International Convention for the Regulation of Whaling. Furthermore, this paper also examines the considerations on the relationship between Science and Law provided in the decision under analysis.
\end{abstract}

Keywords: International Court of Justice. International Environmental Law. Whaling in Antarctic Case 